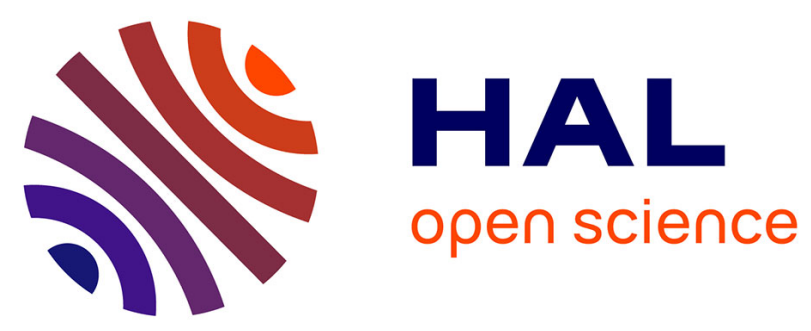

\title{
Modelling the role of oral processing on in vivo aroma release of white rice: Conceptual model and experimental validation
}

\author{
Muhammad Syahmeer How, Jim R Jones, Marco P Morgenstern, Eli \\ Gray-Stuart, John E Bronlund, Anne Saint-Eve, Ioan-Cristian Trelea, Isabelle \\ Souchon
}

\section{To cite this version:}

Muhammad Syahmeer How, Jim R Jones, Marco P Morgenstern, Eli Gray-Stuart, John E Bronlund, et al.. Modelling the role of oral processing on in vivo aroma release of white rice: Conceptual model and experimental validation. LWT - Food Science and Technology, 2021, 141, pp.110918. 10.1016/j.lwt.2021.110918. hal-03120245

\section{HAL Id: hal-03120245}

\section{https://hal-agroparistech.archives-ouvertes.fr/hal-03120245}

Submitted on 25 Jan 2021

HAL is a multi-disciplinary open access archive for the deposit and dissemination of scientific research documents, whether they are published or not. The documents may come from teaching and research institutions in France or abroad, or from public or private research centers.
L'archive ouverte pluridisciplinaire HAL, est destinée au dépôt et à la diffusion de documents scientifiques de niveau recherche, publiés ou non, émanant des établissements d'enseignement et de recherche français ou étrangers, des laboratoires publics ou privés. 


\title{
Modelling the role of oral processing on in vivo aroma release of
}

\section{white rice: Conceptual model and experimental validation}

*Muhammad Syahmeer How ${ }^{1,2,3}$, Jim R. Jones ${ }^{1}$, Marco P. Morgenstern ${ }^{2,4}$, Eli Gray-Stuart ${ }^{1}$, John E. Bronlund ${ }^{1,2}$, Anne Saint-Eve ${ }^{5}$, Ioan Cristian Trelea ${ }^{5}$, Isabelle Souchon ${ }^{6}$

1. Department of Chemical and Bioprocess Engineering, School of Food and Advanced Technology, Massey University, Palmerston North, New Zealand

2. Riddet Institute, Palmerston North, New Zealand

3. Department of Process and Food Engineering, Faculty of Engineering, Universiti Putra Malaysia, Selangor Darul Ehsan, Malaysia

4. New Zealand Institute for Plant and Food Research, Lincoln, New Zealand

5. Université Paris-Saclay, INRAE, AgroParisTech, UMR SayFood, F-78850, ThivervalGrignon, France

6. UMR408 SQPOV, INRAE, Avignon Université, F-84000 Avignon, France

*Corresponding author email address: M.How@massey.ac.nz / how.syahmeer@gmail.com

\begin{abstract}
A conceptual model was developed to relate oral processing parameters and aroma release of cooked white rice. The conceptual model indicates that aroma release is dependent on the increase of particle surface area, the dilution effect of saliva and the diffusion of aroma from food residues that can be trapped in the buccal-pouches in the mouth. The model was validated against in vivo retro-nasal aroma release data during the consumption of rice flavoured with two aroma compounds (2-nonanone and ethyl propanoate) by five panellists. The oral processing behaviour of each subject was characterised at four different stages during oral processing by measuring bolus particle size, saliva content and the amount of residue particles that could be washed from the mouth after bolus expectoration. The results showed that aroma release for all subjects were dependent on the particle breakdown pathways used in
\end{abstract}


oral processing. Subjects who reduced the rice to smaller particle sizes, higher pasted fraction and higher bolus residues had higher aroma release as expected from the conceptual model. Accounting for the physiological variables of subjects, the physicochemical parameters of aroma compounds and using a larger number of subjects in future studies will improve the model reliability.

Keywords;

Chewing; Starch food; Flavour release; Particle size; Mechanistic modelling

\section{Introduction}

Understanding the link between oral processing and aroma release is important as this knowledge can be used to formulate foods (varying the food composition or structure) to achieve a desired flavour profile, taking into account individual or group differences in their physiology and mastication behaviour (Harrison, Campbell \& Hills, 1998). Previous studies have mostly focused on dairy food products (e.g. cheese) to study the influence of food oral processing on aroma release among European subjects (Doyennette et al., 2014; Feron et al., 2014; Guichard, Repoux, Qannari, Labouré \& Feron, 2017; Labouré, Repoux, Courcoux, Feron \& Guichard, 2014). To our knowledge, no previous studies have looked at the influence of the food oral processing of rice on retro-nasal aroma release. The consumption of white rice has been shown to significantly increase the risk of type 2 diabetes, especially in Asian (Chinese and Japanese) populations (Hu, Pan, Malik \& Sun, 2012). In some parts of Asia, such as Malaysia and Singapore, rice is often flavoured with liquid products of high fat content, such as coconut milk and chicken broth or fried with high amounts of vegetable cooking oil, causing obesity issues (Lani, Matsor, Nasution, Ku \& Yusof, 2015; Nidhi et al., 2010; Umachandran, Sawicka, Nasir \& Pasqualone, 2018). These problems are ubiquitous to all the major starchbased diets (Lani et al., 2015; Nidhi et al., 2010; Umachandran et al., 2018). Thus, there is a 
need to formulate and design starch-based food so that they are not only healthier but also sensorially desirable.

Mechanistic models can be a useful tool to predict aroma release and therefore are a key step in understanding, for example, the role of the product (e.g. composition and structure), and the consumer (e.g. physiological parameters and individual experience) in the perceived flavour (Harrison et al., 1998; Trelea et al., 2007; Doyennette et al., 2011, 2014; Déléris, SaintEve, Saglio, Souchon \& Trelea, 2016). Additionally, they can also be used to understand the role of oral processing in flavour release, as well as to help design food products taking into account physiological characteristics of individuals (e.g. young or older people, or a people with clinical pathologies such as dysphasia) (Trelea et al., 2007). Consequently, aroma release models can be used to identify the most influential physiochemical, anatomical and physiological parameters affecting this release (Trelea et al., 2007).

In this paper, we propose a conceptual model describing the mechanistic relationship between several oral processing parameters and aroma release during the consumption of cooked white rice. While the physiological characteristics of individuals and physicochemical parameters of aroma compound can affect aroma release, these aspects will not be considered in this short paper but will be considered in future manuscripts to improve model complexity. To test the validity of the conceptual model, we measured the dynamics of oral processing parameters (e.g. bolus saliva content, particle size distribution (PSD) and bolus residues) and aroma release parameters of five panellists in vivo at different stages of mastication. The results of the in vivo measurements were then compared against the conceptual model.

\section{Conceptual model development}

Figure 1 shows a simple conceptual diagram relating oral processing parameters and aroma release from rice in this study. The first factor is the effect of bolus particle size distribution 
(PSD) on aroma release. When food particles are reduced in size during mastication, the surface area of the food increases dramatically, allowing a greater proportion of the flavour to be released from the food matrix into the surrounding saliva (Harrison et al., 1998).

We assumed that the breakdown of a cooked rice particle follows a 'cleave and paste' mechanism (Figure 2) where when a rice kernel is occluded between opposing molars, one or a few large particles are produced, and a fraction of the original kernel is pasted into very fine particles (paste) which become effectively part of the liquid phase of the bolus (Gray-Stuart, 2016). It was found in the study by Gray-Stuart (2016) that during the mastication of rice, the bolus forms a bimodal particle size distribution when measured using a laser diffraction method. Particles with a size less than $0.355 \mathrm{~mm}$ were not broken down any further in subsequent chewing cycles. Pasting involves swelling of granules and it is known that native rice starches have granule sizes in the range of 1.9 to $26 \mu \mathrm{m}$ (Desam, Li, Chen, Campanella \& Narsimhan, 2020). During cooking the granule can swell 2 to 48 times of their initial size when heated to various temperatures (Lii, Tsai \& Tseng, 1996). The swelling of starch granules can be enhanced with increasing shear rate (Svegmark \& Hermansson, 1991) and the presence of excess water (Rao, Okechukwu, Da Silva \& Oliveira, 1997). It follows that this smaller mode in the particle size distribution $(<0.355 \mathrm{~mm})$ corresponds to individual separated swollen starch granules.

It is expected that subjects who produce boluses with smaller particles and pasted fractions will have created more surface area and so are expected to perceive higher retro-nasal aroma release intensities due to a faster release and movement of the taste and aroma compounds from the food matrix into the saliva and vapour phases.

Aroma release can also be affected by the bolus moisture/saliva content. Subjects who have high saliva production rates are expected to have a weak perception of aroma release because 
the saliva will coat, absorb and dilute the flavour compounds as they release from the food matrix during mastication (Doyennette et al., 2014). As the bolus becomes saturated with saliva, the interfacial area between the bolus surface and the air present in the oral cavity will reduce, further slowing the rate of aroma release.

Lastly, subjects who have more food residues trapped in the buccal-pouches in the mouth are likely to perceive a more intense and lingering aroma release. The driving force for transfer of volatile aroma compounds across the interface is the equilibrium difference in flavour concentration between the food/saliva mixture and air phase under mouth conditions. A combination of broken and unbroken rice particles that are trapped inside the buccal-pouches of the mouth will allow more diffusion from the rice-saliva mixture to the gas phase by as a result of these concentration gradients. This analysis completes the simple conceptual model which forms the hypotheses of expected oral processing behaviour to compare against experimental data collected in human subjects.

\section{Data collection}

Five healthy subjects ( 1 male and 4 female, aged between 24 and 40 years) were recruited for the study. All subjects had good overall health, good natural dentition, and no dentures or prosthetic teeth. None of the subjects were taking any medication that could affect muscle function or saliva flow. Subjects gave their written informed consent to participate in the study. They were asked not to eat or drink for at least one hour before each session.

\subsection{In vivo oral processing experiments}

In a total of three sessions, each subject was asked to masticate and expectorate rice samples at various mastication stages to determine oral processing parameters (number of chews, chewing time, bolus PSD, bolus moisture content, the amount of saliva added and the amount of residual particles that could be washed from the mouth). 


\subsubsection{Test food}

White Jasmine rice (Oryza sativa L.) was purchased from a local supermarket (Auchan, Plaisir, France). Rice was cooked using a 1:2 ratio (125 g rice in $250 \mathrm{~g}$ water (Evian, Danone, France)) in a 2.6 L Microwave rice steamer (1110 style, Sistema®, New Zealand) using a microwave (MS23F300EAW model, Samsung, Malaysia) at $900 \mathrm{~W}$ for 9 minutes. Approximately $5 \mathrm{~g}$ of cooked rice samples were transferred into small containers and were kept warm at $60^{\circ} \mathrm{C}$. The rice was served to the subjects after cooling down to approximately $50^{\circ} \mathrm{C}$, which is the temperature at which rice is usually consumed (Moongngarm, Bronlund, Grigg \& Sriwai, 2012; Gray-Stuart, 2016).

\subsubsection{Number of chews and oral processing time at swallow point}

The oral processing time before swallowing for all subjects was measured from the point when the $5 \mathrm{~g}$ rice sample was placed in the mouth and stopped when the subjects raised their hand to indicate they were ready to swallow. The number of chews taken to reach the swallowing point was counted by observing the upward and downward movements of the chin. Triplicate trials were performed for each subject, and the average value was calculated.

\subsubsection{Bolus collection}

Each subject participated in two individual sessions of 30 minutes for bolus collection. One session was dedicated to bolus PSD measurements and one session for the bolus moisture content. Boluses were expectorated and collected at 25\%, 50\%, $75 \%, 100 \%$ of the average total number of chews required by each subject to swallow (section 3.1.2). The number of chews were counted and the subjects were asked to chew normally until instructed to expectorate their bolus (expectorated in Erlenmeyer flask (250 mL, Duran, Germany) for PSD analysis and aluminium dishes for moisture content). The flask containing the bolus for PSD measurement was stored in a box filled with ice to minimise salivary amylase action. All analyses were 
performed on the same day. Triplicate trials were performed for each subject in randomised order.

\subsubsection{Particle size distribution}

The PSD of the bolus samples was analysed by image analysis as described by Jourdren et al. (2016). Particle images were acquired using a Canon EOS 700D camera (Canon Inc., Japan) and a ScanCube 308 (Altawak Technologie, France). The PSD analysis was performed using ImageJ (version 1.52a, National Institutes of Health, USA). A black and white threshold was applied to the images, which provided the projected area $\left(\mathrm{mm}^{2}\right)$ of individual particles. A characteristic circular shape was assumed to predict the particle equivalent diameter from the projected area. The median equivalent diameter $d 50(\mathrm{~mm})$, the quartiles $d 75(\mathrm{~mm}), d 25(\mathrm{~mm})$ and the interquartile ratio $d 75 / d 25$ (no unit) were obtained. The volume of the particles below a threshold size of $0.355 \mathrm{~mm}$ was summed to calculate the volume of bolus which was considered pasted (Gray-Stuart, 2016). The pasted fraction was defined as the ratio of the volume of pasted particles and the total volume of particles measured.

\subsubsection{Bolus moisture content, the amount of saliva incorporated and the amount of residual bolus after expectoration}

The moisture content of the expectorated bolus ( $\mathrm{g}$ per $100 \mathrm{~g}$ of bolus) was determined in triplicate for each mastication stage as described above by drying the bolus samples in an oven at $110^{\circ} \mathrm{C}$ for a minimum of 15 hours (Jourdren et al., 2017). The moisture content of the cooked rice was determined in the same way. The amount of incorporated saliva in the bolus (g saliva per $100 \mathrm{~g}$ of dry matter) and the amount of rice remaining in the mouth after expectoration (w/w \% residues) were calculated as described by Drago et al., (2011); Motoi, Morgenstern, Hedderley, Wilson \& Balita, (2013) from the moisture contents of the bolus and of the cooked rice and the weight of the expectorated bolus. 


\subsection{In vivo aroma release of rice}

\subsubsection{Rice flavouring}

A preliminary in vitro aroma release analysis was performed to select and identify potential target aroma compounds in the cooked rice.

The first part of the in vitro test was conducted using a Dynamic Headspace (DHS) Gas Chromatography (GC) coupled with a Mass Spectrometer (MS) (DHS : MPS autosampler, Gerstel, Mülheim an der Ruhr, Germany, GC: Agilent 7890B, MS: Agilent 5977B MSD, Agilent Technologies, Santa Clara, USA). The measurement protocol was carried out as follows. Approximately $3 \mathrm{~g}$ of cooked rice samples were weighed and placed in a $20 \mathrm{~mL}$ vial (Gerstel, Mülheim an der Ruhr, Germany). Each sample was then incubated at $40^{\circ} \mathrm{C}$ for $3 \mathrm{~min}$ with agitation at $500 \mathrm{rpm}$. The headspace was then purged with a constant flow of helium at $30 \mathrm{~mL} / \mathrm{min}$ for $10 \mathrm{~min}$ at $30^{\circ} \mathrm{C}$ and aroma compounds were trapped on an adsorption unit (Tenax TA). The trap was dried for 6 minutes under a stream of helium to remove traces of water. Then the trap unit was desorbed from $30^{\circ} \mathrm{C}$ to $270^{\circ} \mathrm{C}$ with a heating rate of $60^{\circ} \mathrm{C} / \mathrm{min}$ and an isotherm of $7 \mathrm{~min}\left(270^{\circ} \mathrm{C}\right)$ in a cool injection system at $-100^{\circ} \mathrm{C}$. The column head injection was carried out from $-100^{\circ} \mathrm{C}$ to $270^{\circ} \mathrm{C}$ with a heating rate of $12^{\circ} \mathrm{C} / \mathrm{min}$ and an isotherm of $5 \min \left(270^{\circ} \mathrm{C}\right)$.

The GC oven temperature was programmed from $40^{\circ} \mathrm{C}$ with an isotherm of $5 \mathrm{~min}$, to $155^{\circ} \mathrm{C}$ with a heating rate of $4^{\circ} \mathrm{C} / \mathrm{min}$, and then to $250^{\circ} \mathrm{C}$ with a heating rate of $20^{\circ} \mathrm{C} / \mathrm{min}$ with an isotherm of $5 \mathrm{~min}$. The GC was equipped with an apolar capillary column (DB-5MS, 60m x $320 \mu \mathrm{m} \times 1 \mu \mathrm{m}$, Agilent Technologies, Santa Clara, USA) and with a helium flow of 1.6 $\mathrm{mL} / \mathrm{min}$ (carrier gas). A mass spectrometer was used to characterise aroma compounds. It was performed in the electron impact mode at $70 \mathrm{eV}$, in a full scan from $\mathrm{m} / \mathrm{z} 29$ to 300 U.M.A. (United Mass Atomic or Dalton). The ionisation source was set at $230{ }^{\circ} \mathrm{C}$ and the quad at $150^{\circ} \mathrm{C}$. The compounds were identified by comparison of their mass spectra with those of the 
NIST 2017 Mass Spectral Library. The retention times were also used for characterization. The data was reported as peak area for each molecule detected. Quantification data were obtained from the integration of the areas from the total ion current (TIC).

The second part of the in vitro test was conducted using a Proton Transfer Reaction Mass Spectrometry (PTR-MS). Ten grams of cooked rice were stored at $37^{\circ} \mathrm{C}$ for $1 \mathrm{hr}$ in 100 mL Schott flasks equipped with valved caps (GL 45, Duran Group, Wertheim, Germany). The highly sensitive PTR-MS apparatus (Ionicon Analytik, Innsbruck, Austria) was operated at a drift tube temperature, voltage and pressure of $60^{\circ} \mathrm{C}, 600.1( \pm 0.4) \mathrm{V}$ and $200( \pm 1) \mathrm{Pa}$, respectively, resulting in a field density ratio $(E / N)$ of $151.4( \pm 1.4 \mathrm{Td})$. The PTR-MS was used in a SCAN mode over a mass range of $m / z, 20-200$ with a dwell time of $100 \mathrm{~ms}$ per peak. In the first five cycles of the measurement (90 s) the volatile compounds in the ambient air (i.e., the background signal) was measured. The next 15 cycles ( $290 \mathrm{~s}$ ) were then dedicated to measuring the sample headspace (Jourdren et al., 2017). The volatile compounds present in the sample headspace were then introduced into the system through a capillary line heated to $110^{\circ} \mathrm{C}$ at a flow rate of $100 \mathrm{~mL} / \mathrm{min}$.

In both in vitro aroma release methods, hexanal, an aroma compound typically found in cooked rice (Buttery, Ling, Juliano \& Turnbaugh, 1983; Wei, Handoko, Pather, Methven \& Elmore, 2017; Dias, Duarte, Mariutti \& Bragagnolo, 2019) had the highest peak area (64\% of the total peak area of all aroma compounds detected). A typical aroma compound in cooked rice, 2-acetyl-1-pyrroline (Buttery et al., 1983; Wei et al., 2017; Dias et al., 2019), was detected in the DHS GC-MS. However due to the unstable nature of the compound in the presence of oxygen and moisture (Pico et al., 2018) this could result in the protonated ion breaking into smaller fragments when PTR-MS is used. The presence of smaller fragmented ions resulting from the reaction in PTR-MS made it challenging to classify ions that belong to the 2-acetyl pyrroline. As a result, only hexanal was selected for monitoring in the preliminary in vivo trial. 
For the preliminary in vivo trial, two subjects were used to monitor the selected ions corresponding to hexanal $(\mathrm{m} / \mathrm{z} 55, \mathrm{~m} / \mathrm{z} 83$ and $\mathrm{m} / \mathrm{z}$ 101) in multiple ion detection (MID) mode during in vivo consumption of rice. All of the selected ions however had weak signals when measured in vivo as the intensity did not seem to differ much from the background noise measured prior to the in vivo trial. Cooked rice is known to have a weak taste and aroma intensity (Nishinari, Fang \& Rosenthal, 2019) and there could be an interaction between the aroma compounds with the oral-pharyngeal-nasal mucosa layers (Déléris et al., 2016) during consumption, which could reduce the intensity of the targeted aroma compounds when measured in the nose air space.

Because of the difficulty to identify hexanal during actual in vivo experiments, the rice was flavoured with 2-nonanone and ethyl propanoate, which are common aroma compounds used in previous studies using PTR-MS and that exist in rice (Déléris et al., 2016; Doyennette et al., 2011; Labouré et al., 2014). Both aroma compounds were food grade (Sigma-Aldrich, Steinheim, Germany). A mixture of $300 \mathrm{ppm}$ of 2-nonanone and ethyl propoanate concentration was prepared by diluting the stock aroma solution with mineral water (Evian, Danone, France). The cooking condition was the same as described for the non-flavoured rice (section 3.1.1), except the water was substituted with the aroma solution.

\subsubsection{In vivo aroma release during oral processing}

The dynamic release of aroma compounds during in vivo experiments was measured using PTR-MS (Ionicon Analytik, Innsbruck, Austria). The PTR-MS instrument was operated at a drift tube temperature, voltage and pressure of $60^{\circ} \mathrm{C}, 600.1( \pm 0.4) \mathrm{V}$ and $200( \pm 1) \mathrm{Pa}$, respectively, resulting in a field density ratio $(E / N)$ of $151.4( \pm 1.4 \mathrm{Td})$ (Doyennette et al., 2014; Jourdren et al., 2017). Measurements were performed with the multiple ion detection mode with a dwell time of $100 \mathrm{~ms}$ per mass. The 2-nonanone compound was monitored with $\mathrm{m} / \mathrm{z}, 143$ and ethyl propanoate with $\mathrm{m} / \mathrm{z} 103$. Acetone $(\mathrm{m} / \mathrm{z}$ 59) was monitored as a breath marker with a 
dwell time of $50 \mathrm{~ms}$ (Doyennette et al., 2011). Masses $\mathrm{m} / \mathrm{z} 21$ (signal for $\mathrm{H}_{3}^{18} \mathrm{O}^{+}$) and $\mathrm{m} / \mathrm{z}, 37$ (signal for water clusters $\mathrm{H}_{2} \mathrm{O}-\mathrm{H}_{3} \mathrm{O}^{+}$) were also monitored (Jourdren et al., 2017).

For each subject, air from the nose space was sampled from two inlets of a stainless steel nosepiece, inserted into the subject's nostrils. The gas produced from the samples was transferred from the nosepiece to the PTR-MS through a capillary line with a mean flow rate of $100 \mathrm{~mL} / \mathrm{min}$, heated at $110^{\circ} \mathrm{C}$. A minimum of five replicates were performed for all in vivo measurements. The release curves were divided into three periods: (i) the phase before the sample was introduced (phase 0); (ii) the phase before the first swallow (phase 1); (iii) the phase after the first swallow (phase 2) (Figure 3). The following quantitative release parameters were extracted: (i) the maximum concentration reached by the aroma compound ( $I_{\max 1}$ and $\left.\mathrm{I}_{\max 2}\right)$; (ii) areas under the curve, $\left(\mathrm{AUC}_{1}\right.$ and $\left.\mathrm{AUC}_{2}\right)$; and (iii) the time at which $\mathrm{I}_{\max }$ occurred ( $\mathrm{T}_{\max 1}$ and $\mathrm{T}_{\max 2}$ ) (Déléris et al., 2016). The AUC and intensity values (I) were also extracted at $25 \%, 50 \%, 75 \%$ and $100 \%$ of the subjects first swallowing point time.

\subsection{Statistical Analysis}

All statistical analysis was carried out with XLStat software (Version 2019.2.2, Addinsoft, New Zealand). A Principal Component Analysis (PCA) was performed on the bolus properties and aroma release parameters to represent the oral breakdown pathways and aroma release dynamics between all five subjects on a 2-dimensional plot.

\section{Results and discussions}

\subsection{The breakdown pathways of subjects}

Detailed results for the bolus properties for all subjects are provided in Appendix A. A PCA analysis was conducted to condense the bolus properties measured in section 3.1 into a two-dimensional plot (Figure 4) to explore the variation of breakdown pathways between the subjects. Figure 4 (a) shows the breakdown pathway taken for each subject with increasing 
chewing time from left to right. By using Figure 4 (b) as a guide, the differences in the rice breakdown pathway taken by each subject can be explained. Plots on the left of Figure 4 (b) show bolus parameters during early mastication stages, featuring large particle size (high $d 75$, $d 50$ and $d 25$ ), low moisture and saliva content, narrow particle size distribution (low $d 75 / d 25$ ), low pasted fraction and low amounts of residue remaining in the mouth. Moving towards the right side of the figure shows the plots of bolus properties towards the later stages of mastication where smaller particle size, higher bolus moisture and saliva content, broader particle size distributions (high $d 75 / d 25$ ), and an increased amount of pasted fraction and residue are present.

The breakdown pathways for subjects A1 and A4 were differentiated from the rest of the subjects in terms of their bolus PSD, moisture content, saliva content and residues (Figure 4 (a)). Subject A1 who took the shortest oral processing time to reach the swallowing point had large bolus PSD parameters $(d 75, d 50$ and $d 25)$, low pasted fraction, low $d 75 / d 25$ and low bolus moisture and saliva contents at swallow point indicating a large particle size and low lubricating bolus threshold for safe swallow. The subject also had the highest amount of bolus residues remaining in the mouth compared to other subjects.

Subject A4 with the longest chewing time, had the smallest bolus PSD parameters, a high amount of pasted fraction, high $d 75 / d 25$ and the highest bolus moisture and saliva content at swallow point. The amount of bolus residue remaining in the mouth for subject A4 was the second largest of all subjects.

Subjects A3 and A5, who spent about the same amount of time chewing, had similar levels of residue, bolus PSD parameters, $d 75 / d 25$ and moisture and saliva contents increase during oral processing. Subject A2 was differentiated from subjects A3 and A5 with a lower amount of bolus residue in the mouth but had similar levels for the remaining bolus parameters. 


\subsection{Aroma release}

Table 1 and Table 2 shows the release parameters of all subjects extracted for 2nonanone and ethyl propanoate respectively. In general, 2-nonanone seemed to have a higher intensity and AUC values for all subjects during chewing and after the first swallow than ethyl propanoate. Subjects A1 and A4 were differentiated from other subjects with higher $I_{\max }$ and AUC values especially during chewing ( $\operatorname{Imax}_{1}$ and $\left.A U C_{1}\right)$ while other subjects had similar $I_{\max }$ and AUC values during oral processing. To illustrate the dynamics of aroma release during multiple stages of oral processing, the aroma release parameters, specifically the AUC and $I_{\max }$ values at $0 \%, 25 \%, 50 \%$ and $100 \%$ of each subject swallowing point were plotted in a PCA diagram (Figure 5). Subjects A4 and A1 are separated from other subjects with a higher aroma release parameters whereas other subjects had a fairly similar trend.

\subsection{Conceptual model validation}

The role of different bolus properties such as bolus PSD, pasted fraction, moisture/saliva content and residues on aroma release discussed in the conceptual model in section 2.0 were then compared against in vivo oral processing and aroma release results as described in sections 4.1 and 4.2.

\subsubsection{Bolus PSD and pasted fraction}

The conceptual model hypothesises that subjects who produce boluses with smaller particles will have created more surface area and so are expected to perceive a higher retronasal aroma release intensities due to a faster release and movement of the taste and aroma compounds from the food matrix into the saliva and air phases. Subject A4 who had the largest aroma release values (Table 1, Table 2 and Figure 5) produced the smallest bolus PSD parameters (i.e. $d 75, d 50$ and $d 25$ ) at swallow point between all subjects (Figure 4a). The pasted fraction for this subject was also among the highest among all subjects. The findings from subject A4 were consistent with the conceptual analysis regarding the impact of bolus PSD on 
aroma release. In contrast, Subject A1, who had the largest bolus particle size parameters $(d 75$, $d 50$, and $d 25$ ) and low bolus pasted fraction had the second-highest aroma release. Theoretically, this subject should have low aroma release parameters due to a reduced surface area as described above, but the opposite was observed. The combination of effects from other bolus properties such as bolus moisture/saliva content and bolus residues may explain the observed behaviour from subject A1. This will be further discussed in the sections below. The other subjects (A2, A3 and A5) all possessed similar trends for aroma release (Figure 5) as their breakdown pathways were fairly similar as seen in Figure $4 a$.

\subsubsection{Bolus moisture and saliva contents}

An increase in bolus moisture/saliva content would dilute the flavour concentrations, as seen in other studies (Harrison et al., 1998; Feron et al., 2014; Jourdren et al., 2017). Subject A4 who had the highest amount of saliva incorporated in the bolus (Figure 4a) still had the largest aroma release values (Table 1 and Table 2) but subject A1, who had the lowest amount of saliva content had the second largest aroma release values. The data observed for subject A1 verifies the conceptual analysis to some extent. This is because despite having large bolus PSD parameters due to a short chewing time, subject A1 had a low saliva content therefore less aroma dilution would have occurred from the increase in saliva.

\subsubsection{Bolus residues}

The conceptual model described the effects of bolus residues where rice particles that are trapped inside the buccal-pouches of the mouth will allow more diffusion from the ricesaliva mixture to the gas phase by the concentration gradients. Subject A1 who had the highest amount of rice bolus residues remaining in the mouth (Figure 4a) had the second largest aroma release values (Table 1, Table 2 and Figure 5). Subject A4, who had the second highest rice bolus residues was observed to possess the highest aroma release parameters. 
The results obtained for the subjects validate the conceptual model due to the combined effects of different bolus properties. For example, it was observed that subject A1 despite having large bolus PSD parameters and low pasted fraction (therefore, a reduced surface area for aroma release), also had the lowest dilution effect from saliva and more diffusion from the rice-saliva mixture to the gas phase by having more bolus residues trapped inside the buccalpouches of the mouth. Subject A4 who had the smallest bolus PSD parameters, high pasted fraction, the highest saliva content, and second highest amount of bolus residues had the largest aroma release values, which also agrees with the conceptual model. It is possible that the effect of bolus PSD and pasted fraction were more dominant than the dilution effect of moisture/saliva content which explains the results of subject A4 who had the highest amount of bolus moisture and saliva contents. The results for the other subjects also somewhat agree with the conceptual model where the dynamics of aroma release results (Figure 5) followed their breakdown pathways as illustrated in Figure 4.

\section{Conclusion}

A conceptual model was proposed to explain the mechanistic relationship between oral processing parameters and aroma release during the consumption of cooked white rice. The validity of the model was then tested by comparing the model against in vivo oral processing and aroma release behaviour data for five different subjects. The results of the in vivo study validated the model where subjects with smaller particle size, higher pasted fraction, and higher amount of residues in their bolus had higher aroma release as expected. In addition, results showed that the dynamic behaviour of aroma release for all subjects followed a similar trend with the breakdown pathways taken for each subject, which further strengthen the validation of the conceptual analysis. The weakness of the developed model here is that it does not take into account physiological factors (e.g. volumes and surface areas of different physiological compartments) and physicochemical parameters of the aroma compound. These aspects will 
be included in future studies to increase model complexity. In addition, a larger number of subjects could also help to increase the model reliability.

\section{Acknowledgements}

The authors would like to acknowledge the Riddet Institute CoRE (Platform 2), INRA and AgroParisTech for their financial support. The authors are also grateful to the support given by Manon Leheup, David Forest, Bridgitte Pollet, Anne-Claire Peron for their help with the in vivo studies, subjects characterisation and analysis in the GC-MS.

\section{Declaration of competing interest}

The authors declare they have no competing interest.

\section{References}

Buttery, R. G., Ling, L. C., Juliano, B. O., \& Turnbaugh, J. G. (1983). Cooked rice aroma and 2-acetyl-1-pyrroline. Journal of Agricultural and Food Chemistry, 31(4), 823-826.

Conde-Petit, B., Escher, F., Nuessli, J. (2006) Structural features of starch-flavor complexation in food model systems. Trends in Food Science \& Technology, 17 (5), 227-235

Déléris, I., Saint-Eve, A., Saglio, A., Souchon, I., Trelea, I.C. (2016) Insights in aroma compound retention by mucosa during consumption through mathematical modelling. Journal of Food Engineering, 190, 123-138.

Desam, G. P., Li, J., Chen, G., Campanella, O., \& Narsimhan, G. (2020). Swelling kinetics of rice and potato starch suspensions. Journal of Food Process Engineering, 43(4), e13353.

Dias, L.G., Duarte, G.H.B., Mariutti, L.R.B., Bragagnolo, N. (2019) Aroma profile of rice varieties by a novel SPME method able to maximize 2-acetyl-1-pyrroline and minimize hexanal extraction. Food Research International, 123, 550-558. 
Doyennette, M., Deleris, I., Saint-Eve, A., Gasiglia, A., Souchon, I., Trelea, I.C. (2011) The dynamics of aroma compound transfer properties in cheeses during simulated eating conditions. Food Research International, 44 (10), 3174-3181.

Doyennette, M., Déléris, I., Féron, G., Guichard, E., Souchon, I., \& Trelea, I.C. (2014). Main individual and product characteristics influencing in-mouth flavour release during eating masticated food products with different textures: Mechanistic modelling and experimental validation. Journal of Theoretical Biology, 340, 209-221.

Drago, S. R., Panouillé, M., Saint-Eve, A., Neyraud, E., Feron, G., \& Souchon, I. (2011). Relationships between saliva and food bolus properties from model dairy products. Food Hydrocolloids, 25(4), 659-667.

Feron, G., Ayed, C., Qannari, E. M., Courcoux, P., Laboure, H., \& Guichard, E. (2014). Understanding aroma release from model cheeses by a statistical multiblock approach on oral processing. PloS one, 9(4), e93113.

Harrison, M., Campbell, S., \& Hills, B. P. (1998). Computer Simulation of Flavor Release from Solid Foods in the Mouth. Journal of Agricultural and Food Chemistry, 46(7), 27362743.

Guichard, E., Repoux, M., Qannari, E., Labouré, H., Feron, G. (2017) Model cheese aroma perception is explained not only by in vivo aroma release but also by salivary composition and oral processing parameters. Food \& Function, 8 (2):615-628

Gray-Stuart, E. M. (2016). Modelling food breakdown and bolus formation during mastication, Massey University, New Zealand (Doctoral dissertation).

Hu, E. A., Pan, A., Malik, V., \& Sun, Q. (2012). White rice consumption and risk of type 2 diabetes: meta-analysis and systematic review. BMJ, 344, e1454. 10.1136/bmj.e1454 
Jourdren, S., Panouille, M., Saint-Eve, A., Deleris, I., Forest, D., Lejeune, P., Souchon, I. (2016) Breakdown pathways during oral processing of different breads: impact of crumb and crust structures. Food \& Function, 7 (3):1446-1457

Jourdren, S., Masson, M., Saint-Eve, A., Panouille, M., Blumenthal, D., Lejeune, P., Déléris, I., Souchon, I. (2017) Effect of bread crumb and crust structure on the in vivo release of volatiles and the dynamics of aroma perception. Journal of Agricultural and Food Chemistry, 65(16), 3330-3340

Labouré, H., Repoux, M., Courcoux, P., Feron, G., Guichard, E. (2014) Inter-individual retronasal aroma release variability during cheese consumption: Role of food oral processing. Food Research International, 64, 692-700.

Lani, M., Matsor, N., Nasution, Z., Ku, P., \& Yusof, A. (2015). Substitution Effects of Coconut Milk with Soymilk on Sensory Acceptance and Shelf Life of'Nasi Lemak'. British Journal of Applied Science \& Technology, 7(4), 377.

Lii, C. Y., Tsai, M. L., \& Tseng, K. H. (1996). Effect of amylose content on the rheological property of rice starch. Cereal chemistry, 73(4), 415-420.

Moongngarm, A., Bronlund, J., Grigg, N., \& Sriwai, N. (2012). Chewing behavior and Bolus Properties as Affected by Different Rice Types. International Journal of Medical and Biological Sciences, 6.

Motoi, L., Morgenstern, M. P., Hedderley, D. I., Wilson, A. J., \& Balita, S. (2013). Bolus Moisture Content of Solid Foods during Mastication. Journal of Texture Studies, 44(6), 468-479.

Nidhi, G., Ming Kai, C., Jingzhen, Y., Balasekaran, G., Michael, C., Robert, N. G., Magdalena Mo Ching, M. (2010). Obesity prevention in Singapore: Collaborative efforts among government, health professionals and the community. 
Nishinari, K,, Fang, Y,, Rosenthal, A. (2019) Human oral processing and texture profile analysis parameters: Bridging the gap between the sensory evaluation and the instrumental measurements. Journal of Texture Studies.

Pico, J., Khomenko, I., Capozzi, V., Navarini, L., Bernal, J., Gómez, M., Biasioli, F. (2018) Analysis of volatile organic compounds in crumb and crust of different baked and toasted gluten-free breads by direct PTR-ToF-MS and fast-GC-PTR-ToF-MS. Journal of Mass Spectrometry, 53 (9):893-902.

Rao, M. A., Okechukwu, P. E., Da Silva, P. M. S., \& Oliveira, J. C. (1997). Rheological behavior of heated starch dispersions in excess water: role of starch granule. Carbohydrate polymers, 33(4), 273-283.

Svegmark, K., \& Hermansson, A. M. (1991). Distribution of amylose and amylopectin in potato starch pastes: effects of heating and shearing. Food Structure, 10(2), 2.

Trelea, I.C., Atlan, S., Déléris, I., Saint-Eve, A., Marin, M., Souchon, I. (2007) Mechanistic mathematical model for in vivo aroma release during eating of semiliquid foods. Chemical Senses, 33 (2),181-192

Umachandran, K., Sawicka, B., Nasir, N. A.-N., \& Pasqualone, A. (2018). Nutritional features of Biryani as the basis for the formation of an entrepreneurial mode in Biryani Market.

van Ruth, S.M., King, C. (2003) Effect of starch and amylopectin concentrations on volatile flavour release from aqueous model food systems. Flavour and Fragrance Journal, 18 (5), 407-416

Wei, X., Handoko, D.D., Pather, L., Methven, L., Elmore, J.S. (2017) Evaluation of 2-acetyl1-pyrroline in foods, with an emphasis on rice flavour. Food Chemistry, 232, 531-544 


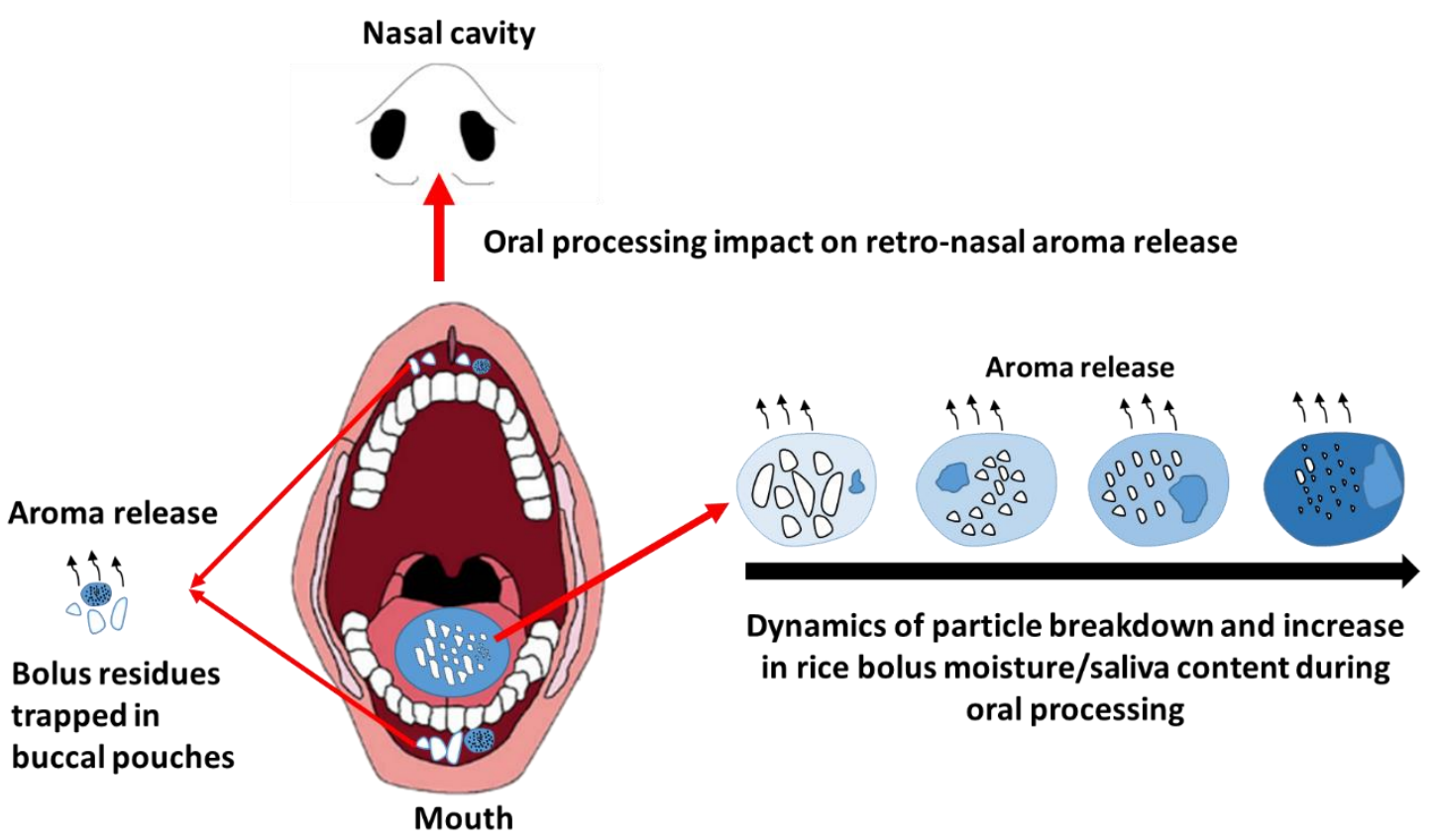

Figure 1: Conceptual model diagram relating the effects of different bolus properties on retronasal aroma release of rice. As chewing time increases, particles are reduced into smaller sizes where a proportion of them are pasted into the liquid phase of the bolus. These particles have significantly large surface area which allow for fast and instant diffusion of aroma release to the saliva phase of the bolus. At the same time, saliva content in the bolus increases and dilute the volatiles. Some particles can also be trapped within the buccal pouches of the mouth (bolus residues) causing further release.

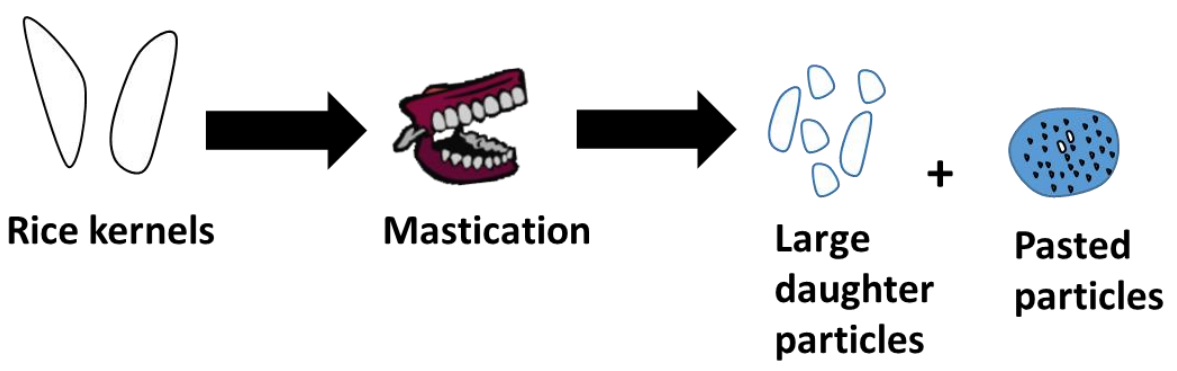

Figure 2: 'Cleave and paste' mechanism during mastication of cooked rice. Particles are cleaved into larger daughter particles and some are pasted into the liquid phase of the bolus. 


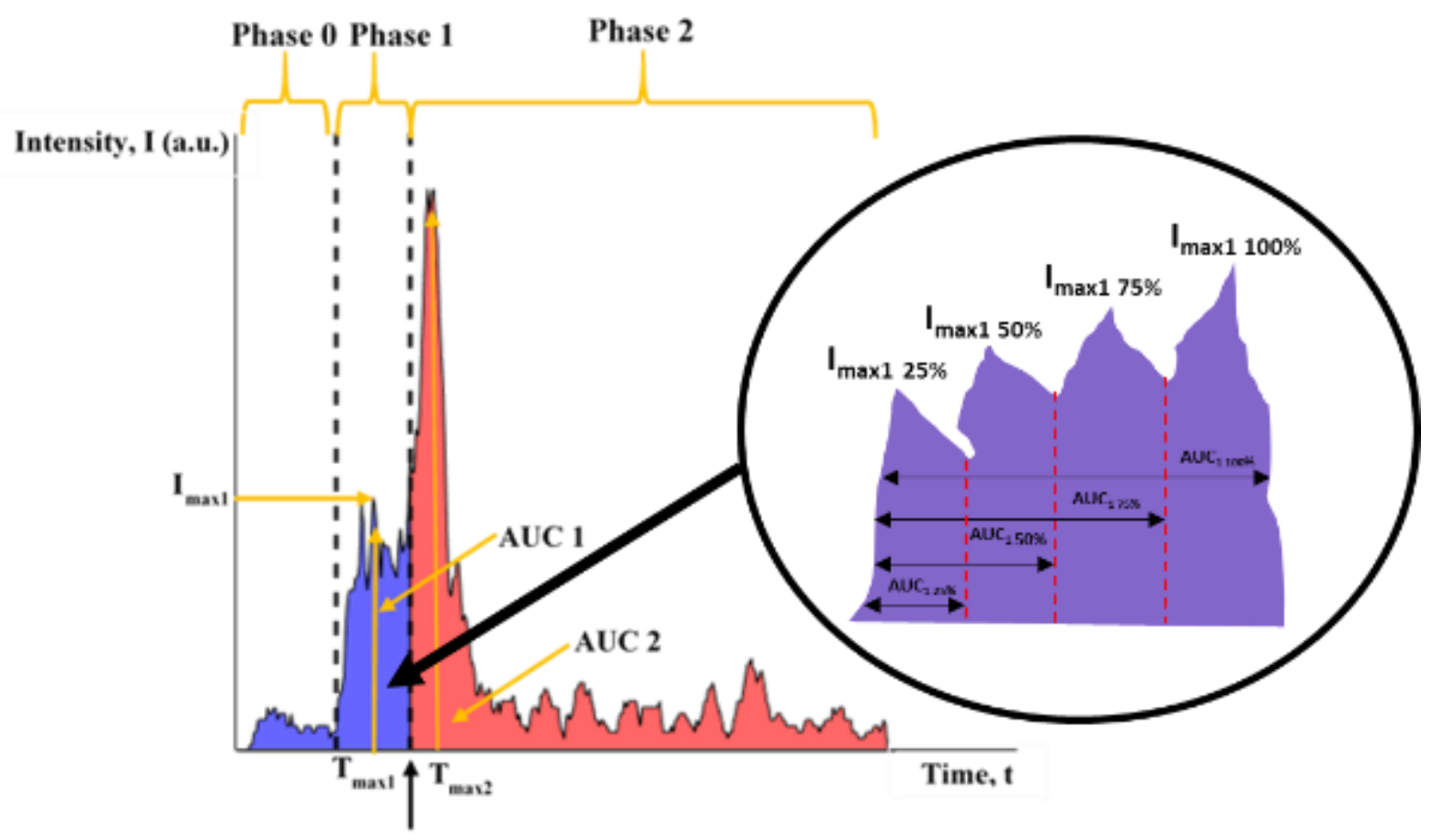

Swallow point

Figure 3: Aroma release curve profile. The total amount of aroma released (AUC 1 \& AUC $2)$, the maximum intensity $\left(I_{\max 1} \& I_{\max 2}\right)$, the time at which $I_{\max }$ occurred $\left(T_{\max 1} \& \mathrm{~T}_{\max 2}\right)$, the average release rate $\left(\mathrm{I}_{\max 1} / \mathrm{T}_{\max 1} \& \mathrm{I}_{\max 2} / \mathrm{T}_{\max 2}\right)$ as well as the intensity and AUC at multiple stages during mastication $(25 \%, 50 \%, 75 \%$ and $100 \%$ of the time when first swallow occured) were determined from the aroma release curve (Image redrawn from Déléris et al. (2016)) 
(a)

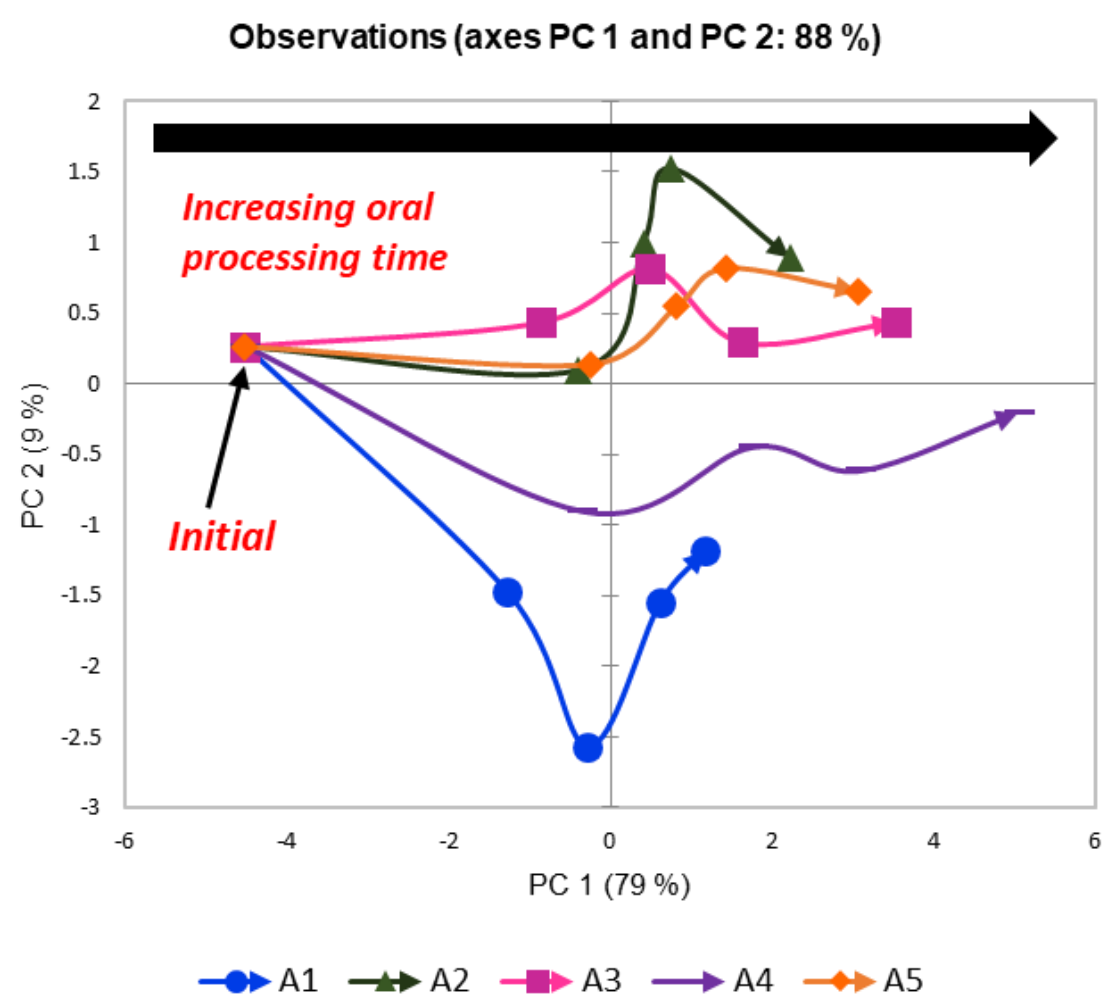

(b)

Variables (axes PC 1 and PC 2: $88 \%$ )

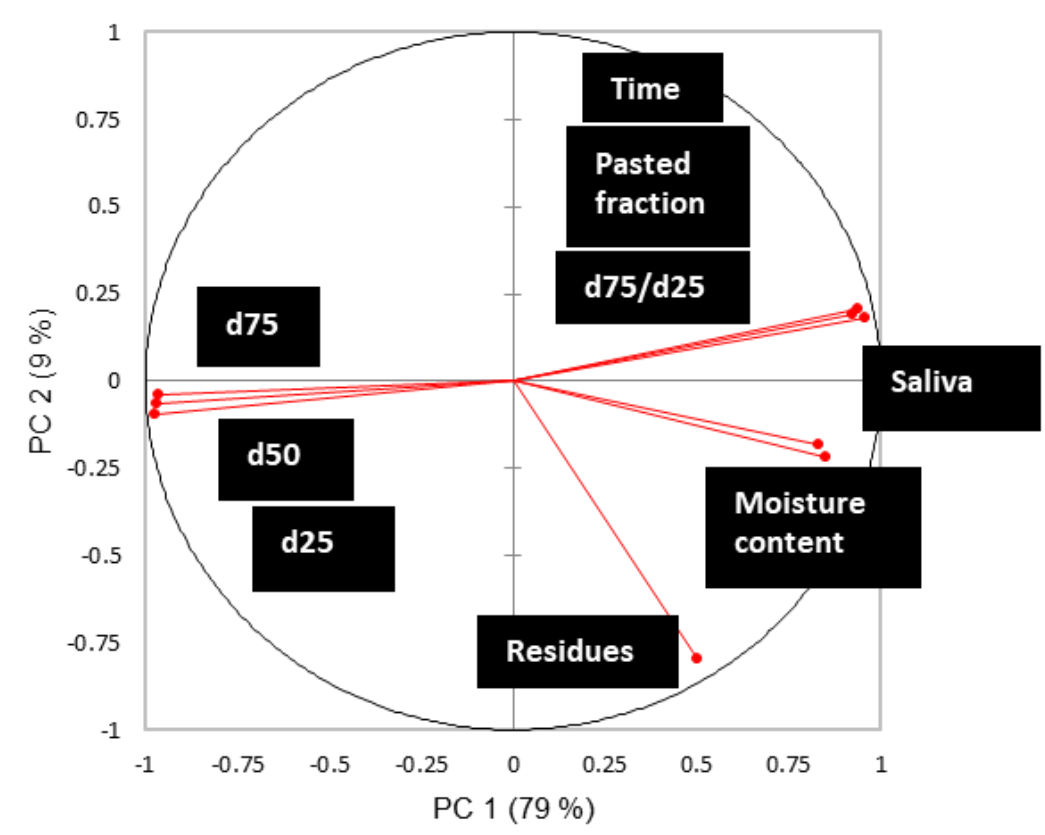

Figure 4: Breakdown pathways of rice during oral processing from PCA analysis. (a) Breakdown path for first two principal components. (b) Factor loadings of the bolus variables measured for all subjects and provides a guide for the breakdown pathway plot in (a). Arrows are drawn from left to right to illustrate the breakdown pathway from the time when samples were introduced in the mouth (initial) to the swallowing point. The points between the initial and swallow point of each subject were the bolus properties at $25 \%, 50 \%$ and $75 \%$ of the subject's total oral processing time. PC 1 separates A4 from the rest due to the subject's high oral processing time whereas PC 2 separates A1 from the others due to a high amount of residues remaining in the mouth. Subject A1: $\longrightarrow$ Subject A2: $\rightarrow$ Subject A3: $\rightarrow$ Subject A4: $\rightarrow$ Subject A5: $\rightarrow$ 
(a)

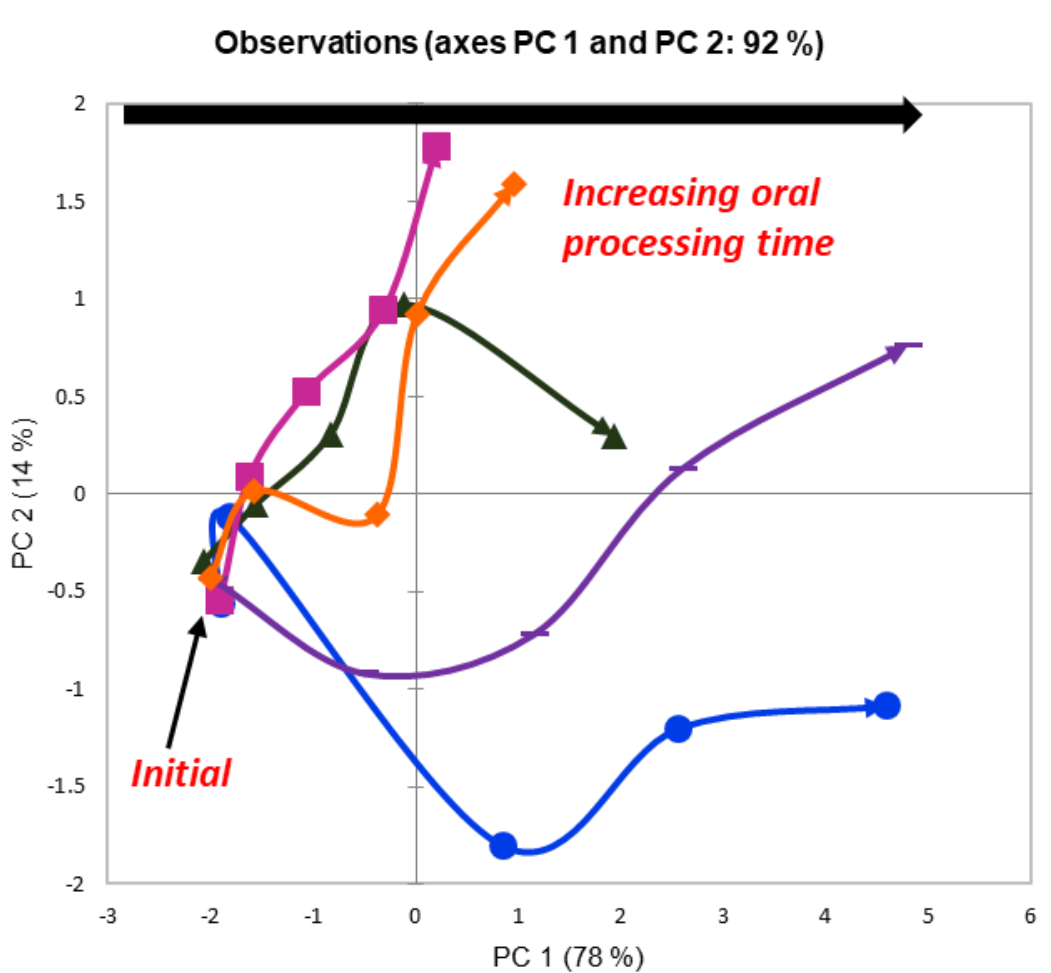

(b)

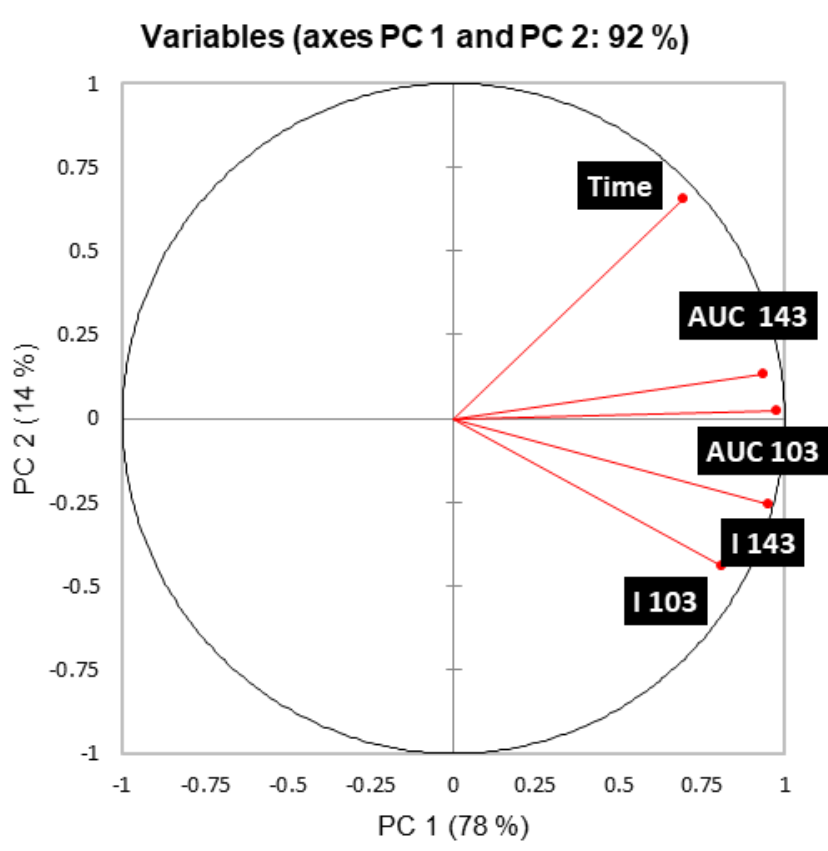

Figure 5: The dynamics of aroma release parameters (AUC and I values) during oral processing between subjects. (a) Plot when PC 1 and PC 2 of the aroma release parameters between subjects were compared. (b) Factor loadings of the aroma release parameters measured for all subjects and provides a guide for the dynamic aroma release plot, in (a). Subject A1 and A4 were differentiated from other subjects with higher I and AUC values while other subjects had fairly similar I and AUC values during oral processing. Subject A1: $\longrightarrow$ Subject A2: $\rightarrow$ Subject A3: $\rightarrow$ Subject A4: $\rightarrow$ Subject A5: 